\title{
Membrane Trafficking Machinery Components Associated with the Mammalian Acrosome during Spermiogenesis
}

\author{
J oão Ramalho-Santos,*` Ricardo D. Moreno,‡ Gary M. Wessel,§ \\ Edward K. L. Chan," and Gerald Schatten*'\|,"
}

\begin{abstract}
*Oregon Regional Primate Research Center, Division of Reproductive Sciences, Oregon Health Sciences University, Beaverton, Oregon 97006; ||Department of Obstetrics and Gynecology and Department of Cell \& Developmental Biology, Oregon Health Sciences University, Portland, Oregon 97201; §Department of Molecular and Cell Biology and Biochemistry, Brown University, Providence, Rhode Island 02912; "W. M. Keck Autoimmune Disease Center, The Scripps Research Institute, La J olla, California 92037; ¥Unit of Reproduction and Developmental Biology, Pontifical Catholic University of Chile, Santiago, Chile; and †Center for Neuroscience and Cell Biology of Coimbra, Department of Zoology, University of Coimbra, 3000 Coimbra, Portugal
\end{abstract}

Active trafficking from the Golgi apparatus is involved in acrosome formation, both by delivering acrosomal contents to the nascent secretory vesicle and by controlling organelle growth and shaping. During murine spermiogenesis, Golgi antigens (giantin, $\beta$-COP, golgin 97, mannosidase II) are detected in the acrosome until the late cap-phase spermatids, but are not found in testicular spermatozoa (maturation-phase spermatids). This suggests that Golgi-acrosome flow may be relatively unselective, with Golgi residents retrieved before spermiation is complete. Treatment of spermatogenic cells with brefeldin A, a drug that causes the Golgi apparatus to collapse into the endoplasmic reticulum, disrupted the Golgi in both pachytene spermatocytes and round spermatids. However, this treatment did not affect the acrosomal granule, and some $\beta$-COP labeling on the acrosome of elongating spermatids was maintained. Additionally, $\mathrm{N}$-ethylmaleimide sensitive factor, soluble NSF attachment proteins, and homologues of the t-SNARE syntaxin and of the V-SNARE VAMP/synaptobrevin, as well as members of the rab family of small GTPases, are associated with the acrosome (but not the acrosomal granule) in round and elongated spermatids. This suggests that rab proteins and the SNARE machinery for membrane recognition/docking/fusion may be involved in trafficking during mammalian acrosome bi ogenesis. ๑2001 Academic Press

Key Words: acrosome; spermatid; Golgi; trafficking; SNARES; NSF; SNAPs; rabs.

\footnotetext{
${ }^{1}$ To whom correspondence and reprint requests should be addressed at Oregon Regional Primate Research Center, Oregon Health Sciences University, 505 NW 185th Avenue, Beaverton, OR, 97006, USA. Tel: (503) 614-3710. Fax: (503) 614-3725. E-mail: schatten@ohsu.edu.
}

\section{INTRODUCTION}

The acrosome is a large vesicle localized as a cap-like structure on the heads of spermatozoa from most species. Release of acrosomal contents occurs during the acrosome reaction, an exocytotic event resulting in the fusion of the acrosomal membrane and the sperm plasma membrane that primes the sperm for zona penetration and sperm- egg binding/fusion (for reviews see $[1,2])$.

Although its biogenesis is an important aspect of mammalian spermiogenesis, the nature of the acrosome itself is still debated. The acidic characteristic of the compartment, as well as its rich hydrolase content, suggests similarities with lysosomes $[3,4]$, possibly even secretory lysosomes found in most cells [5-7]. However, some typical lysosomal markers are not present on the acrosome [8], which raises the possibility that it might more accurately be described as a modified secretory granule. Nevertheless, the acrosome is a complex organelle that includes several structurally and biochemically distinct regions [9-11], and its growth and shaping relies on intense membrane trafficking, possibly involving both clathrincoated [12, 13] and COPI-coated [13-15] vesicles.

During mammalian spermiogenesis several distinct stages of spermatid differentiation also reflect differences in the nascent acrosome [16, 17]. The initial Golgi phase is marked by fusion of Golgi-derived dense proacrosomal granules (which contain some, but not all, acrosome components) into a single acrosomal granule that attaches to the cell nucleus. During the cap phase, fusion of many (presumably Golgi-derived) vesicles takes place around the granule, forming the acrosomal vesicle. This initially rounded vesicle spreads over the nucleus concomitant with Golgi apparatus migration to the opposite cell pole. In both these stages the spermatid nucleus maintains a round mor- 

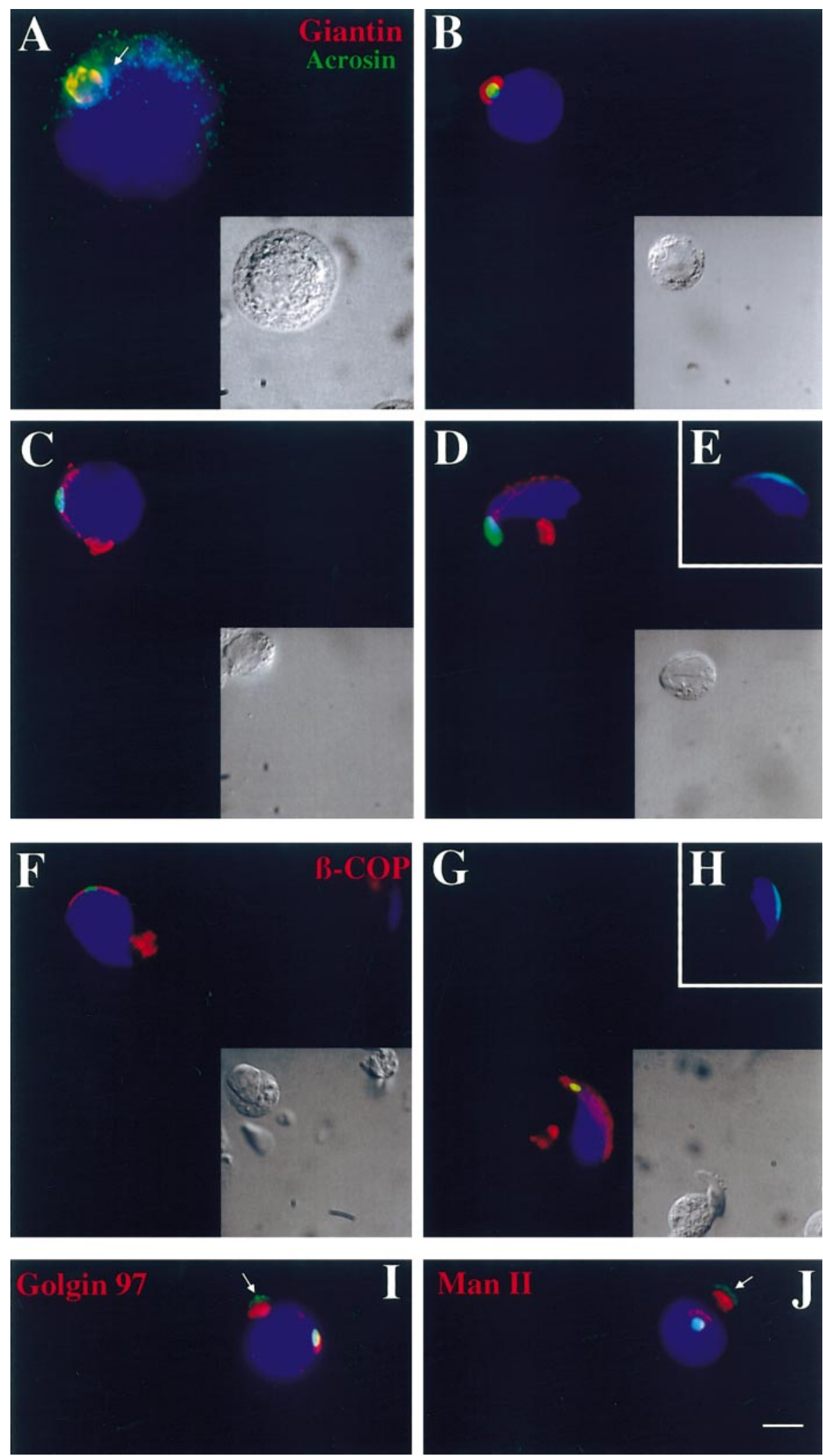

FIG. 1. Golgi markers label the acrosome until late in spermiogenesis. Golgi proteins (red) can be found in the acrosome of mouse spermatids. Giantin (A-E) brightly labels the Golgi apparatus throughout spermi ogenesis [(A) spermatocyte; (B) Gol gi-phase spermatid; (C) cap-phase spermatid; (D) acrosome-phase spermatid], but can also be found on the acrosome of both round (C, cap-phase) and elongating (D, acrosome-phase) spermatids, but not in the mature organelle found in epididymal sperm (E). Similarly, $\beta$-COP labels the Golgi complex in 


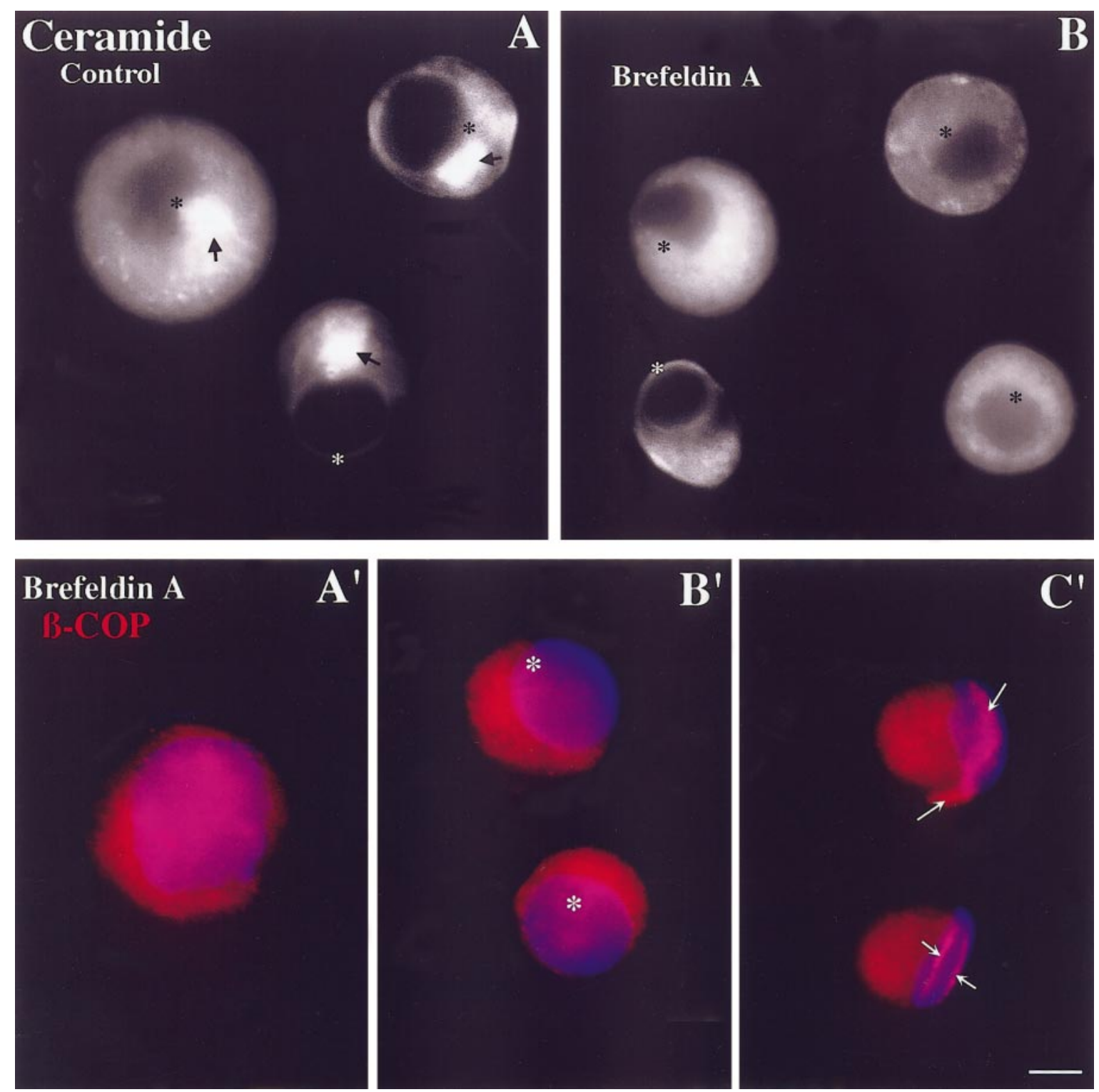

FIG. 2. Effect of brefeldin A on the Golgi apparatus and acrosome of spermatogenic cells. (A,B) Live imaging of mouse round spermatids labeled with the fluorescent lipid BODIPY-ceramide before (A) and after (B) incubation with brefeldin $A$. The presence of a bright patch of fluorescence in control cells indicates an active Gol gi apparatus ( $A$, arrows); asterisks mark the position of the acrosomal granule. ( $A^{\prime}, B^{\prime}, C^{\prime}$ ) I mmunocytochemistry of fixed spermatogenic cells foll owing brefel din A treatment. $\beta$-COP labeling is diffuse in spermatocytes ( $A^{\prime}$ ) and round spermatids $\left(\mathrm{B}^{\prime}\right)$. In el ongating spermatids $\left(\mathrm{C}^{\prime}\right)$ some $\beta$-COP is still present on the acrosome (arrows), although no characteristic Gol gi pattern is visible. Asterisks mark the position of the acrosomal granule and the bar represents $5 \mu \mathrm{m}$.

phology. During the acrosome phase the spermatid begins to elongate as the manchette microtubules start to grow from the nuclear ring. The acrosome reaches its final shape at the end of the maturation phase, and most of the cytoplasm and organelles are discarded in the cytoplasmic droplet/residual body [16, 17].

spermatocytes (not shown) and spermatids ( $F$ and $G$ ). As in the case of giantin, $\beta$-COP is also present in the acrosome of round (F) and elongating (G) spermatids, but cannot be detected in mature sperm (H). The acrosomal granule is visualized using acrosin (green) and persists in a distinct apical area of the acrosome in elongated spermatids (D, G), spreading only into the entire organelle of mature sperm $(E, H)$. Other specific Golgi markers such as golgin $97(\mathrm{I})$ and mannosidase II $(\mathrm{J})$ also can be found on the acrosome, albeit with a fainter labeling pattern. In some instances acrosin is not completely sorted to the acrosomal granule and faintly labels the Gol gi apparatus (A, I, J , arrows). DNA is shown in blue. Insets are light-microscopy images of each of the cells depicted; bar represents $5 \mu \mathrm{m}$. 
Although synthesis of acrosomal proteins may take place or begin before spermiogenesis [9], the acrosome is initially formed in close association with the Golgi apparatus in Golgi-phase spermatids, with a continuous and intense flow of membranes in the endoplasmic reticulum-Golgi-acrosome direction [10, 18-23]. The bulk of acrosome components seem to be del ivered from the Golgi at this stage [24], but membrane trafficking continues after the organelle has detached from the acrosomal area and initiated its migration to the opposite cell pole [21]. I $n$ fact, the Golgi is biologically active until it degenerates and is ultimately discarded in the cytoplasmic droplet [21]. On the other hand, acrosome maturation proceeds throughout spermiogenesis and is completed during epididymal transit [9]. Membrane trafficking in spermatids is thus mostly directed toward acrosome biogenesis, with components sorted via the Golgi complex, albeit with possible exceptions. While some authors have described an acrosomal protein that seems to follow an ER-to-acrosome pathway bypassing the Golgi [25], others have suggested that endocytic trafficking might also contribute to the organelle [15]. However, very little data exist to corroborate these non-Golgi trafficking routes.

We initiated this study by addressing the puzzling fact that some Gol gi-specific antigens seem to be found in the acrosome at several stages of spermiogenesis [4, $13,26]$. In parallel, we have set out to characterize components of the membrane trafficking machinery present during acrosome biogenesis, in an attempt to identify molecular players potentially active in the recognition/docking/fusion of the membrane vesicles that will ultimately form the organelle. For this purpose we have used the framework of the SNARE (SNAP receptor) hypothesis for membrane recognition (for reviews see [27-29]), which postulates that a specific protein on a vesicular carrier (or v-SNARE) interacts with a complementary protein on a target membrane/vesicle (tSNARE) to ensure proper docking/fusion. Although many additional proteins/components seem to modulate this process $[28,29]$, SNAREs are important in defining membrane trafficking events in somatic cells. We had previously determined that SNARE homologues can serve as markers for the acrosome of late round spermatids [4, 30]. These findings have been extended here to describe the continuing presence of these proteins throughout acrosome biogenesis, thus suggesting a possible role for SNARE proteins in membrane trafficking necessary for the maturation of this organelle. In addition, we were also able to establish that the ATPase NSF ( $\mathrm{N}$-ethylmaleimi de sensitive factor), as well as its cofactor/effector alfa-SNAP (soluble NSF attachment protein), is also present on the acrosome. Although its precise function in SNARE-pair formation or disassembly prior to/following membrane fusion is debated, NSF is important for many traffick- ing events and was indeed the first component of the SNARE model to be identified (for reviews see [27-29]). Additionally, recent work suggests that the ATPase activity of NSF can itself promote membrane fusion [31], although these results have been questioned [32]. Very recently this ATPase was also suggested to have a role in exocytosis during the acrosome reaction [33].

Other important regulators of membrane trafficking are the members of the rab family of small GTPases $[29,34]$. These proteins play a crucial role in determining that transport vesicles will fuse with their appropriate targets [34, 35]. Although rab3A has recently been shown to be present on the acrosome of mature sperm, and modulate the acrosome reaction [33, 3639], the knockout mouse for this protein is fertile [40], and the possible presence of rabs in the developing acrosome has not been explored. We describe here that rab6, rab5, and rab7, but not rab3A, are found in association with the acrosome during the early stages of spermiogenesis and may also play a role in the biogenesis of this organelle.

\section{MATERIALS AND METHODS}

Chemicals. All chemicals were obtained from Sigma Chemical Co (St. Louis, MO), unless otherwise stated.

Antibodies. Rabbit polyclonal antibodies against VAMP and syntaxin were generated against conserved sequences in these proteins. F or VAMP, conserved sequences between rat cellubrevin rat VAMPs 1 and 2 and Drosophila synaptobrevin were used. For syntaxin, conserved sequences between syntaxins $1 \mathrm{~A}$ from rat and from Drosophila were used [41]. Additionally, specific antibodies against syntaxin $1 A$, syntaxin $1 B$, and VAMP/synaptobrevin 1 and 2 were obtained from Synaptic Systems (Göttingen, Germany). Antibodies against syntaxin 2 , syntaxin 6 , syntaxin 13 , rBet1, membrin, and GOS28 (GS28) were obtained from StressGen (Victoria, BC, Canada); antibodies against syntaxin 4 and syntaxin 6 were from Transduction Laboratories (Lexington, KY). Antibodies directed against rab1A, rab2, rab3A, rab5, rab6, rab7, rab8, rab11, and rabaptin-5 were from Santa Cruz Biotechnology (Santa Cruz, CA). Additional probes against rab5 were obtained from CalBiochem (La J olla, CA) and CytoSignal (Irvine, CA), against rab6 from CalBiochem, and against rab7 from CytoSignal. Antibodies against NSF and alfaSNAP were purchased from both Synaptic Systems and Santa Cruz Biotechnology (in this case probes raised against both the $\mathrm{N}$ - and the C-terminus of these molecules were obtained). For control purposes blocking peptides for the NSF, $\alpha$-SNAP, rab5, rab7, and rab6 antibodies were also obtained (Santa Cruz).

Monoclonal antibodies against acrosin were a kind gift from Dr. Claudio Barros, Pontifical Catholic University of Chile, and a monoclonal antibody against the mouse protein sp56, related to the guinea pig acrosomal matrix protein AM67 [42], was obtained from QED Bioscience (San Diego, CA). Anti-giantin and anti-golgin 97 were prepared as described previously [43-45]. Antibodies against TGN 38 and $\beta$-COP were from Affinity Bioreagents, Inc. (Golden, CO), and anti-mannosidase II rabbit serum was a kind gift from Dr. Kelley Moremen, University of Georgia (Athens, GA).

Isolation of spermatogenic cells. Spermatogenic cells were isolated from adult mouse testes using previously described methodology [46]. Briefly, the testes were dissected into a petri dish with EKRB (enriched Krebs-Ringer bicarbonate) medium containing $120.1 \mathrm{mM} \mathrm{NaCl}, 4.8 \mathrm{mM} \mathrm{KCl}, 25.2 \mathrm{mM} \mathrm{NaHCO}, 1.2 \mathrm{mM} \mathrm{KH}_{2} \mathrm{PO}_{4}$ 
(pH 7.2), $1.2 \mathrm{mM} \mathrm{MgSO}{ }_{4} \cdot 7 \mathrm{H}_{2} \mathrm{O}, 1.3 \mathrm{mM} \mathrm{CaCl}_{2}$, supplemented with $11.1 \mathrm{mM}$ glucose, $1 \mathrm{mM}$ glutamine, $10 \mathrm{ml} / \mathrm{L}$ MEM essential amino acid solution (Sigma), $10 \mathrm{ml} / \mathrm{L}$ BME nonessential amino acid solution (Sigma), $100 \mu \mathrm{g} / \mathrm{ml}$ streptomycin, and $100 \mathrm{U} / \mathrm{ml}$ penicillin (K salt). Dry collagenase was then added at a final concentration of $0.5 \mathrm{mg} / \mathrm{ml}$, and the testes were incubated for $15-45 \mathrm{~min}$ at $32^{\circ} \mathrm{C}$ with gentle stirring. Once the seminiferous tubules were dispersed in the medium they were allowed to settle at the bottom of the dish, and the medium was aspirated and discarded. The tubules were then placed in fresh EKRB containing $1 \mu \mathrm{g} / \mathrm{ml}$ DNase I and $0.25 \mu \mathrm{g} / \mathrm{ml}$ trypsin and incubated for 15-45 min with stirring and gentle pipeting. Rel eased spermatogenic cells were pelleted by centrifugation (10 $\mathrm{min}$ at $500 \mathrm{~g}$ ) and washed twice in EKRB before being attached to polyL-lysine-coated coverslips. Mouse sperm was isolated from adult mouse epididymis and attached to poly-L-lysine-coated coverslips before fixation (see below).

For isolation of rhesus monkey spermatogenic cells ERKB medium was replaced with TALP-Hepes (modified Tyrode lactate medium with pyruvate and albumin) containing $114 \mathrm{mM} \mathrm{NaCl}, 3.2 \mathrm{mM} \mathrm{KCl}$, $2 \mathrm{mM} \mathrm{CaCl}_{2}, 0.5 \mathrm{mM} \mathrm{MgCl}_{2}, 25 \mathrm{mM} \mathrm{NaHCO}_{3}, 0.4 \mathrm{mM} \mathrm{NaH}{ }_{2} \mathrm{PO}_{4}, 10$ $\mathrm{mM}$ sodium lactate, $6.5 \mathrm{IU}$ penicillin $/ \mathrm{ml}, 25 \mu \mathrm{g} / \mathrm{ml}$ gentamicin, 6 $\mathrm{mg} / \mathrm{ml}$ fatty acid-free bovine serum albumin, $0.2 \mathrm{mM}$ pyruvate, and buffered with $10 \mathrm{mM}$ Hepes at $\mathrm{pH} 7.4$ [47]. Testes were obtained from fertile males undergoing necropsy, and spermatogenic cells were released by gentle mincing with fine forceps, as described previously [30]. The cells were pelleted by centrifugation (10 $\mathrm{min}$ at $500 \mathrm{~g}$ ) and attached to poly-L-lysine-coated coverslips.

Live imaging of the Golgi apparatus. Mouse spermatogenic cells attached to coverslips were placed in EKRB medium containing the fluorescent lipid BODIPY FL-C5-Ceramide (Molecular Probes, Eugene, OR) at $5 \mu \mathrm{M}$ and incubated at $4^{\circ} \mathrm{C}$ in the dark for $2 \mathrm{~h}[13,48]$. The coverslips were then washed with fresh EKRB and further incubated for $0.5-1 \mathrm{~h}$ at $32^{\circ} \mathrm{C}$ and the cells visualized by epifluorescence microscopy.

Brefeldin A treatment. Coverslips containing mouse spermatogenic cells were placed in EKRB medium containing the fungal metabolite brefeldin A (Epicentre Technologies, Madison, WI) at $15-50 \mu \mathrm{M}$ and incubated at $32^{\circ} \mathrm{C}$ for $1-4 \mathrm{~h}$. In some cases cells were previously labeled with BODIPY FL-C5-ceramide as described above, to visualize Golgi apparatus disruption in live cells. Following brefeldin A treatment coverslips were fixed and processed for immunocytochemistry as described below. For these experiments comparisons were al ways drawn with control cells incubated under the same conditions as the treated cells, but in the absence of the drug. These control cells showed the same patterns as freshly isolated cells. Prior to fixation treated and untreated cells looked similar under light microscopy. No increased cell rupture or vacuolarization was detected with treated cells.

Immunocytochemistry. For immunocytochemistry coverslips with mouse or rhesus spermatogenic cells were placed in PBS containing $2 \%$ formaldehyde and fixed for $1 \mathrm{~h}$. Following fixation, the samples were permeabilized for 60 min in PBS containing 1\% Triton $\mathrm{X}-100$, and nonspecific reactions were blocked by further incubation in PBS containing $2 \mathrm{mg} / \mathrm{ml}$ bovine serum albumin and $100 \mathrm{mM}$ glycine. For labeling, the antibodies were solubilized in this blocking solution and incubated with the coverslips for 1-2 $\mathrm{h}$ at the appropriate dilutions. For rab proteins the incubation was carried out overnight, at $37^{\circ} \mathrm{C}$ [39]. After extensive washing in PBS containing $0.1 \%$ Triton X-100, the samples were sequentially labeled with either TRITC- or FITC-conjugated (Zymed, San Francisco, CA) or Alexa488 or Alexa-568 (Molecular Probes) appropriate secondary antibodies for $1 \mathrm{~h}$ and the DNA stain 4', 6'-diamino-2-phenylindole (Molecular Probes) for $5 \mathrm{~min}$. Following these incubations, coverslips were mounted in VectaShield mounting medium (Vector Labs, Burlingame, CA) and sealed with nail polish. Samples were examined with a Zeiss Axiophot or a Nikon Eclipse E 1000 epifluorescence-equipped microscope operated with Metamorph software.
For antibody specificity control purposes NSF, SNAP, rab5, rab7, and $4 a b 6$ antibodies from Santa Cruz were preincubated $\left(1-2 \mathrm{~h}, 4^{\circ} \mathrm{C}\right)$ with their respective blocking peptides, before being used for immunocytochemistry as described above.

SDS-PAGE and Western blot. For clearer identification of the molecules present during acrosome biogenesis extracts were pre pared by overnight incubation of spermatogenic cell suspensions in extraction buffer ( $1 \mathrm{M} \mathrm{NaCl}, 1 \mathrm{mM}$ EDTA, $10 \mu \mathrm{g} / \mathrm{ml}$ PMSF, $1 \% \mathrm{v} / \mathrm{v}$ Triton X-100, $20 \mathrm{mM}$ Tris- $\mathrm{Cl}, \mathrm{pH} 7.0$ ), and collection of the clear supernatant following centrifugation.

Samples for Western blot were run on SDS-PAGE gels (Ready Gels, Bio-Rad, Hercules, CA) under reducing and denaturing conditions (20-50 $\mu$ g protein/lane) and then transferred to Hybond sheets (Amersham, Buckinghamshire, England) using a dry system at 0.8 $\mathrm{mA}$ per $\mathrm{cm}^{2}$. Hybond sheets were blocked with PBS containing $2 \%$ nonfat dry milk (Carnation, Nestlé, Glendale, CA) for $1 \mathrm{~h}$ and then incubated overnight at $4^{\circ} \mathrm{C}$ with the various primary antibodies at the appropriate dilutions (1/200 to 1/1000). After extensive washing in PBS containing $0.2 \%$ Tween 20 , the blots were incubated with anti-rabbit or anti-mouse goat IgG or anti-goat donkey IgG, tagged with horseradish peroxidase. The bands were developed using the ECL Plus system (Amersham) and Kodak X-OMAT LS Film (Sigma). Purified rab7 and rab5 (CytoSignal) were used as controls when samples were tested for these proteins.

\section{RESULTS}

\section{Golgi Proteins Label the Acrosome Late in Mouse Spermiogenesis}

Using two well-known Golgi markers, giantin (Figs. $1 \mathrm{~A}-1 \mathrm{E}$ ) and $\beta$-COP (F igs. $1 \mathrm{~F}-1 \mathrm{H}$ ), as well as the acrosomal granule marker acrosin $[49,50]$, we have found that both label the Golgi apparatus of murine spermatogenic cells. However, these proteins, which are also present in COPI vesicle coats, can also be conspicuously found on the acrosome (but not the acrosomal granule) of round (Figs. $1 \mathrm{C}$ and $\mathrm{IF}$ ) and elongating (Figs. ID and 1G) spermatids. This observation was confirmed with other Golgi markers, including golgin 97 (Fig. 1I) and the Gol gi resident protein mannosidase II (Fig. 1J ), suggesting that the presence of Golgi proteins on the acrosome might constitute a general motif during spermiogenesis. In the case of mannosidases, a similar observation was made in rat spermatids for mannosidase IA, but not mannosidase II or IB, using different antibodies [26].

The fact that giantin and $\beta$-COP persist on the acrosome in elongating spermatids, when the vesicle has almost reached its final form (Figs. 1D and $1 G$ ), is in contrast to previous observations in the rhesus monkey $[4,13]$ and in rats [14]. However, these proteins are no longer detected on the mature vesicle in epididymal sperm (Figs. $1 E$ and $1 \mathrm{H}$ ), but can still be found in the discarded cytoplasmic droplets, possibly as part of the degenerated Golgi apparatus (data not shown). This acrosomal pattern in elongating spermatids may have been previously overlooked since a bright Golgi label might obscure the acrosome signal. Indeed, the presence of Golgi markers on the acrosome was more evi- 

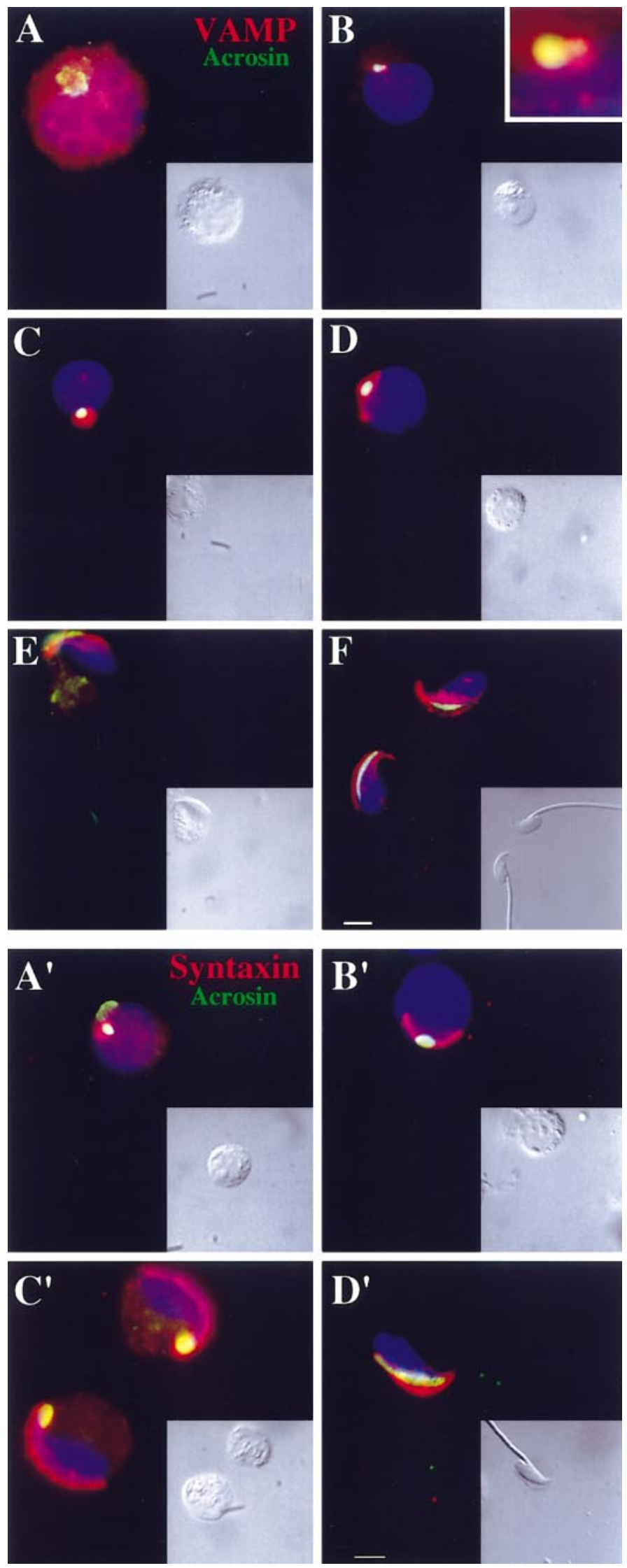

dent when the Golgi had detached from the vesicle and initiated its migration to the opposite cell pole (compare Fig. 1B with $1 \mathrm{C}$ and $\mathrm{IF}$ ).

It is also interesting to note that acrosomal granule contents (as followed by acrosin staining) spread out from a distinct area within the acrosome (the acrosomal granule itself) into the entire acrosome late in spermiogenesis (Figs. 1D and 1G). This is consistent with previous observations [50], but contrasts with what takes place for other acrosomal components [51, 52], such as sp56 (see Fig. 7). A portion of the enzyme also seemed to persist on the outer rim of the Golgi apparatus in some cases (Figs. 1 l and 1 J , arrows), with the same pattern observed in spermatocytes (Fig. 1A, arrow), suggesting that not all acrosin is delivered to the acrosome. Due to its faint label in spermatocytes, acrosin staining in these cells often resulted in a high cytoplasmic background, which was also found in control experiments (secondary antibody alone, data not shown).

\section{Brefeldin A Disrupts the Golgi Apparatus \\ in Mouse Spermatogenic Cells}

Using the fluorescent lipid BODIPY-ceramide in round spermatids (Fig. 2A), we were able to visualize the Golgi apparatus, but not the acrosome [15]. Cell treatment with the fungal metabolite brefeldin A (15 $\mu \mathrm{M}, 1 \mathrm{~h}$ ) resulted in Golgi fragmentation, as monitored by both live ceramide imaging ( $\mathrm{Fig} .2 \mathrm{~B}$ ) and immunofluorescence of spermatocytes ( $F$ ig. $2 A^{\prime}$ ) and round

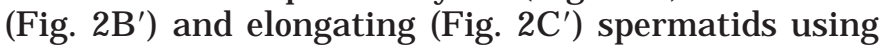
$\beta$-COP as a marker (compare with Figs. $1 F$ and $1 G$ ). The Golgi apparatus is most likely redistributed into the endoplasmic reticulum, as has been described for both somatic cells [53] and spermatids [13, 15]. The acrosomal granule itself was also not affected by the drug (Figs. 2B' and $C^{\prime}$ ), as previously noted [15]. Surprisingly, brefeldin A treatment did not fully remove $\beta$-COP from the acrosome of elongating spermatids (Fig. $2 \mathrm{C}^{\prime}$, arrows), even at higher drug concentrations (up to $50 \mu \mathrm{M}$ ) and following longer (up to $4 \mathrm{~h}$ ) incuba-

FIG. 3. The V-SNARE VAMP/synaptobrevin and the t-SNARE syntaxin label the acrosome throughout spermatogenesis. VAMP (red; $A-F$ ) shows a diffuse labeling pattern in spermatocytes (A) but envelopes both proacrosomal $(B$, inset top right details the proacrosomal granule area) and acrosomal (C) granules (acrosin-green) and labels the acrosome during spermiogenesis in round (B-D) and elongating (E) spermatids. The acrosome label persists in epididymal sperm (F). Similarly syntaxin (red; $A^{\prime}-D^{\prime}$ ) shows a diffuse pattern in spermatocytes (not shown) and can be found in the acrosome (but not the acrosomal granule) throughout spermiogenesis ( $A^{\prime}$ and $B^{\prime}-$ round spermatids; $C^{\prime}$ - el ongating spermatids) and in mature sperm $\left(D^{\prime}\right)$. Black and white insets are light-microscopy images of each of the cells depicted. DNA is shown in blue. Bars represent $5 \mu \mathrm{m}$. Bar in $F$ refers to $A-F$; bar in $D^{\prime}$ refers to $A^{\prime}-D^{\prime}$. 

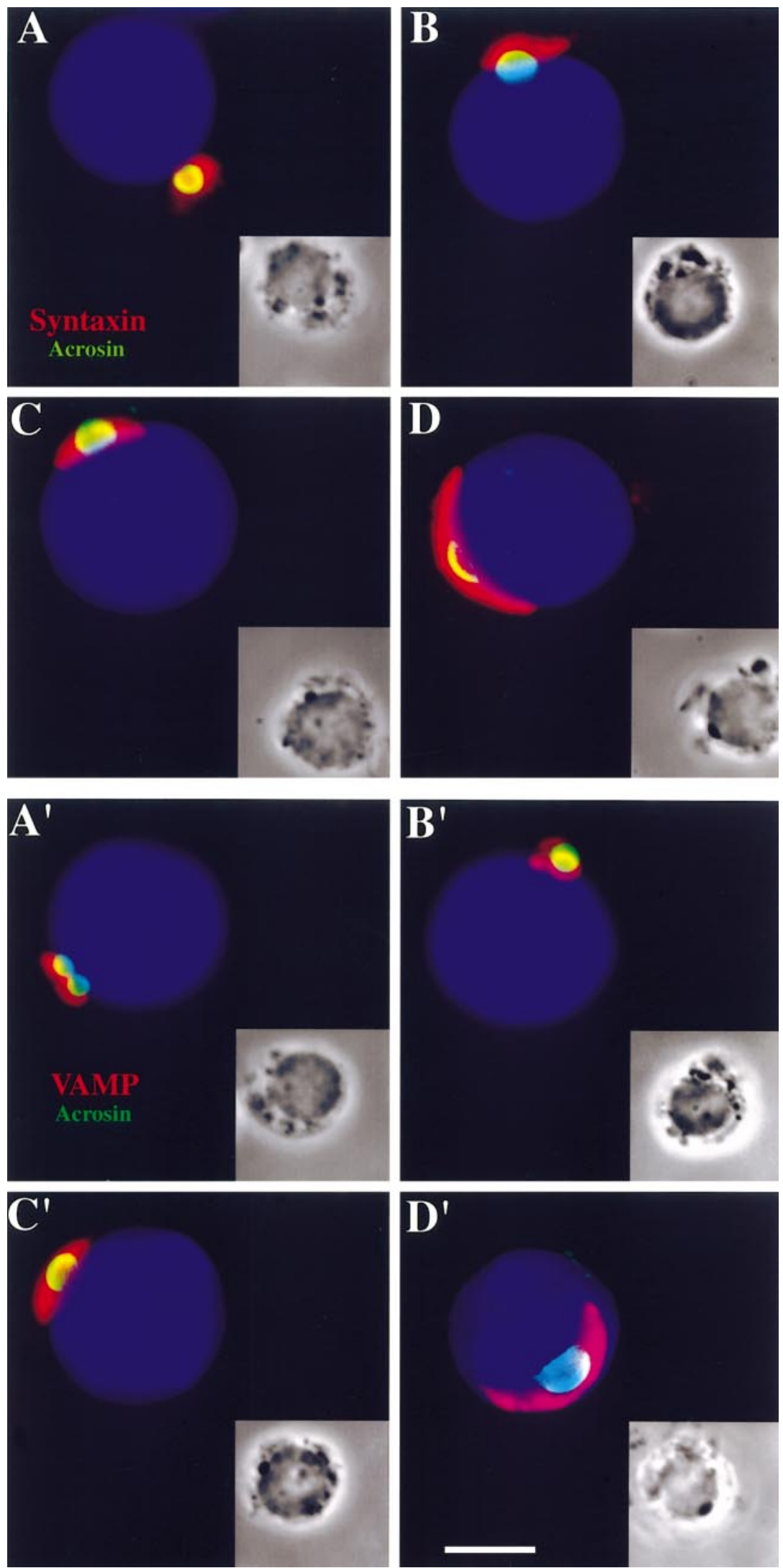

FIG. 4. SNARE homologues are present in the rhesus monkey acrosome. Syntaxin (A-D, red) and VAMP ( $A^{\prime}-D^{\prime}$, red) are also present on the devel oping acrosome of rhesus macaque round spermatids, envel oping the acrosomal granule (acrosin-green) from very early on (A, $A^{\prime}, B, B^{\prime} ; A^{\prime}$ shows two proacrosomal granules that have yet to coalesce), until the acrosome flattens over the nucleus (C, D, $\left.C^{\prime}, D^{\prime}\right)$. DNA is shown in blue. Insets are light-microscopy images of each of the cells depicted; bar represents $5 \mu \mathrm{m}$. 
tion times (data not shown), suggesting that the Golgi and acrosome pools of $\beta$-COP may be differentially sensitive to the drug. This observation may be related to the discovery of two morphologically different types of $\beta$-COP-containing vesicles in the Golgi apparatus of rat spermatids [14].

Potential activity of brefeldin A, as well as of other disruptive drugs, must be viewed with great care, and controls must always be performed (in this case with ceramide and $\beta$-COP, bona fide Golgi markers) to confirm that changes observed are significant and reliable. Indeed, preliminary results seem to suggest that the effect of agents that perturb Golgi structure and membrane traffic may be both cell- and species-dependent ([54], R. D. Moreno and J. Ramalho-Santos, unpublished observations).

SNARE Homologues, NSF, SNAPs, and Rab Proteins are Present on the Acrosome during Mammalian Spermiogenesis

The effect of brefeldin A on the Golgi apparatus in mouse spermatogenic cells suggests that membrane trafficking events in this system closely mirror what takes place in somatic cells. It is therefore likely that other common players in intracellular membrane flow might be active during spermiogenesis. Given that homologues of syntaxin and VAMP are present in mature mammalian spermatozoa of a variety of species [55], we attempted to define the localization of these proteins during the initial steps of acrosome biogenesis.

Both the V-SNARE VAMP (Figs. 3A-3F) and its complementary t-SNARE syntaxin (Figs. 3A'-3D') were distinctively present on the acrosome as soon as it was visible and persisted on this organelle throughout spermiogenesis. Although labeling in spermatocytes was diffuse (Fig. 3A, for VAMP; data not shown for syntaxin) SNAREs could be detected surrounding proacrosin granules (Fig. 3B), and the fully formed acrosomal vesicle (Figs. $3 C$ and $3 A^{\prime}$ ), although there was never colocalization with acrosin. SNAREs persisted on the acrosome of round spermatids as it spread and flattened over the nucleus (Figs. 3D and $3 \mathrm{~B}^{\prime}$ ) and could also be found in elongating spermatids (Figs. 3E and 3C'). However, unlike Golgi antigens which seem to share a similar staining pattern in spermatids (see above), SNARE homologues persisted in the acrosome of both testicular (not shown) and mature epididymal sperm (Figs. 3F and 3D'), consistent with previous observations [55].

Since the presence of Golgi antigens on the acrosome at different stages of spermiogenesis may be speciesdependent ([13], see above) we attempted to use other mammalian spermatogenic cells to confirm the presence of SNARE homologues during the formation of this modified secretory vesicle. Using the rhesus mon- key (Macaca mulatta) [56], we were indeed able to confirm syntaxin and VAMP localization on the acrosome (but not the acrosomal granule) throughout spermiogenesis (Fig. 4). We also could not establish any extensive SNARE labeling in the Golgi area using a marker for the trans-Golgi network (TGN) (Fig. 5), either when the organelle was in close proximity to the acrosome (Figs. 5A and 5A') or at later stages, when it had al ready migrated to the opposite cell pole (Figs. 5B and $\left.5 B^{\prime}\right)$. This suggests that, if not exclusively present in the acrosome, SNARE homologues are at least concentrated in this organelle, consistent with the fact that acrosome formation constitutes the main process involving intracellular membrane trafficking/fusion reactions during mammalian spermiogenesis or, alternatively, that SNAREs in this cell are co-opted specifically for secretion. As evidence for this latter hypothesis we were able to establish that antibodies against syntaxin 1 (both $A$ and $B$ isoforms) and VAMP1, SNAREs active in synaptic vesicle exocytosis [57], labeled the acrosome with the same pattern as shown in Fig. 3 (data not shown). This is consistent with our previous results, showing that these SNAREs are present in the acrosome of mature mammalian sperm [55]. Using the same methodology we were able to detect rBet1 [58], GOS28 [59], or membrin [60], SNARE s active in ER-to-Golgi transport, on the Golgi apparatus, but not on the acrosome (data not shown). Distinct syntaxins $(2,4,6$, and 13$)$ were also not found on the acrosome with the antibodies available (data not shown). However, these results do not exclude the possibility that other SNAREs might be present in the developing organelle.

The presence of SNAREs during acrosome development suggests that the ATPase NSF could also be present, and possibly play a role, in this process. In spermatocytes, NSF showed a diffuse cytoplasmic label with a slight concentration in an area reminiscent of the Golgi apparatus (Fig. 6A). Strikingly, in haploid round spermatids NSF was mostly localized to the acrosomal vesicle and, in later stages, the acrosome, as it spread over the nucleus (Figs. 6B-6D). Additionally, alfa-SNAP, one of the soluble NSF attachment proteins that mediate NSF activity, was also found on the acrosome of round spermatids (Figs. 6E-6F). Staining was inhibited by preincubating NSF and $\alpha$-SNAP antibodies with the respective blocking peptides. These results again stress that acrosome biogenesis is the main membrane trafficking event taking place in these cells.

Finally, the presence of rab proteins on the acrosome was also determined (Fig. 7), using several distinct probes for each member of the rab family (see Materials and Methods). Rab6 was detected mainly on the Golgi apparatus [34], with a fainter acrosomal label (Figs. 7A-7C). Since rab6 mediates a COPI-indepen- 
dent Golgi-to-ER recycling pathway [61, 62], its presence on the acosome may therefore reflect retrograde retrieval of Golgi proteins from the acrosome using this alternative to COPI vesicles. However, it should be noted that this protein has also been found to associate with some types of secretory granules [63]. On the other hand rab8 (functional in the trafficking of TGNdrived vesicles to the basolateral membrane in polarized epithelial cells) and rablA (active in the ER and early Golgi) were not found on the acrosome with the probes available (data not shown).

Given recent debates, regarding both the possible contribution of the endocytic pathway during acrosomal maturation [15] and the nature of the organelle itself, we also tested several rab proteins known to function in endosomes and lysosomes. Accordingly, rab5-positive vesicles were found in close proximity to the acrosome, notably in cap-phase round spermatids (Figs. 7E-7G), and rabaptin-5, a downstream effector for rab5 [64], showed a similar distribution pattern (data not shown). Rab5 is involved in trafficking at the early stages of the endocytic pathway, notably in clathrin-coated vesicles and early endosomes [34, 35, 65]. Interestingly rab7 was also found associated with the organelle in a very similar pattern (Figs. 7I-7K). Rab7, unlike rab5, is present in late, and not early, endosomes $[34,35]$ and has recently been shown to play a role in lysosome biogenesis [66]. Staining for rab6, rab5, and rab7 was replicated using several different probes for each protein (see Materials and Methods) that detect single bands of the expected molecular weight (Fig. 7). Additionally, labeling was inhibited by preincubating anti-rab antibodies with their respective blocking peptides. This suggests that rab6, 5, and 7 are indeed present on the acrosome, although the possibility that the antibodies recognize similar (possibly even testis-specific) proteins cannot be ruled out.

The only member of the rab family that has been actually characterized in the acrosome of mature sperm so far is rab3A [33, 37-39]. Curiously, although this protein could indeed be detected in the mature acrosome of epididymal sperm (data not shown), it was not found on the developing organelle in either round (not shown) or el ongating (Fig. 7M) spermatids. Staining in elongating spermatids was reminiscent of the manchette microtubules (Fig. 7M), suggesting that rab3A might be transported to the acrosome late in spermiogenesis.

\section{DISCUSSION}

In this study we have extended previous findings [4, $13,14,26$ ] to show that several types of Golgi proteins are present in the mouse acrosome until late in spermiogenesis, but cannot be detected in mature spermatozoa. These proteins include both components of ve- sicular carriers (giantin, $\beta$-COP) and resident Golgi antigens (golgin 97, mannosidase II). Since both giantin (macrogolgin) and $\beta$-COP are found in COPI-coated vesicles $[44,67]$ it is likely that their presence on the acrosome of elongating spermatids reflects vesicular transport to the acrosome and/or recycling of Golgi antigens from this organelle back to the Gol gi. As Gol gi antigens are not present in the acrosome of mature sperm, recycling should occur up to the final stages of spermatid maturation, given that the Golgi is still biologically active [21]. Mannosidase IA, for example, has been shown to reside in the rat acrosome of spermatids up to stage 15 [26]. A rab6-dependent, COPIindependent, retrieval pathway may also participate in this process. A distinct explanation for these findings is that all Golgi antigens, rather than being retrieved, are degraded in the acrosome. However, since these proteins are still found in the cytoplasm and degenerating Golgi apparatus present in cytoplasmic droplets, this degradation process would have to be acrosome-specific, which seems unlikely.

According to the hypothesis that the Golgi apparatus is an actively trafficking organelle in this system, treatment of spermatogenic cells with the drug brefeldin A disrupted the Golgi even at the elongating spermatid stage. However, a pool of $\beta$-COP on the acrosome seemed at least partially refractive to the drug. This finding is somewhat surprising, considering that brefeldin A acts directly on COPI coat recruitment to membranes [67], via specific ADP-ribosylation factor (ARF) exchange factors [68, 69], and may reflect the presence of differentially sensitive pools of membranebound $\beta$-COP (possibly related to different ARFs or ARF exchange factors) in mouse spermatids. In accordance with this model, two types of $\beta$-COP-containing vesicles/buds have been described in relation to the Golgi apparatus and acrosome of rat spermatids [14]. Additionally, together with the presence of rab5-containing vesicles in close proximity to the acrosome, this observation might reflect a contribution of the endocytic pathway to the maturation of this organelle, since $\beta$-COP has also been shown to associate with endosomes [70]. In fact, COPI-coated vesicles are involved in the early endocytic pathway in somatic cells [71, 72]. However, these vesicles show a different subunit composition, compared with COPI vesicles involved in Golgi-to-ER transport [71]. Together with possible differences in specific ARFs, or ARF exchange factors, this could hel p explain the differential effects of brefel$\operatorname{din} \mathrm{A}$ in spermatids.

The possible implications stemming from the presence of many different types of Golgi proteins on the acrosome during spermiogenesis have never been adequately addressed. One likely hypothesis is that Golgi residents are missorted to the acrosome, possibly due to a less reliable trafficking machinery [4, 13]. How- 

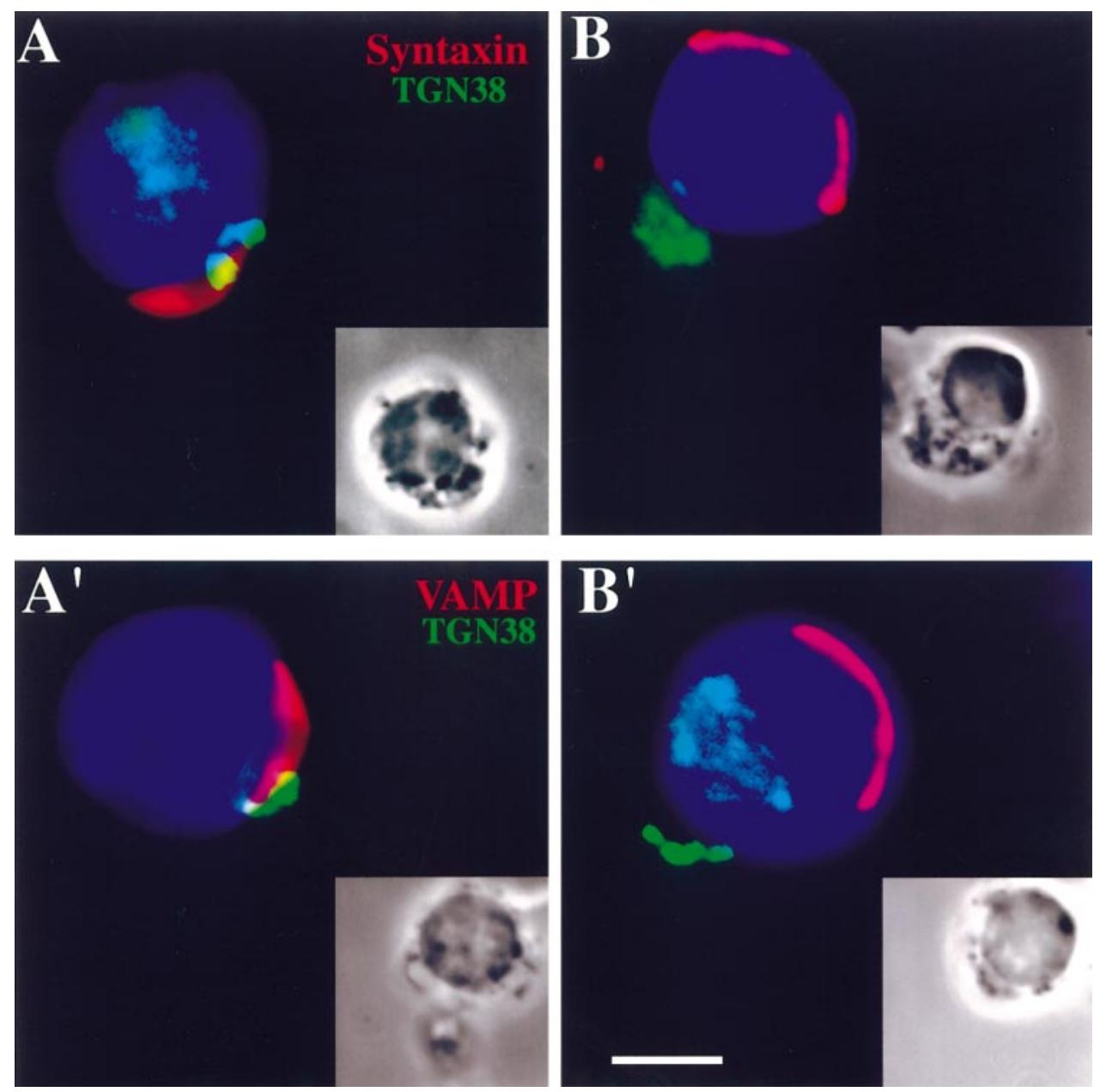

FIG. 5. SNAREs and acrosome shaping during Golgi apparatus migration. Localization of the trans-Golgi labeled with anti-TGN38 (green) during acrosome flattening in the rhesus monkey. The acrosome (red) is brightly labeled with syntaxin (A, B) and VAMP (A', B'), which do not colocalize with the Golgi. DNA is shown in blue. Insets are light-microscopy images of each of the cells depicted; bar represents $5 \mu \mathrm{m}$.

ever, this explanation fails to account for the fact that Golgi proteins are actively removed from the acrosome (either by trafficking or degradation) before spermiogenesis is complete. If Golgi-to-acrosome trafficking was indeed unreliable and error prone, several of the Golgi residents tested would be expected to localize, at some level, to the acrosome of mature sperm, which is not the case ([4], this study). An alternative hypothesis may perhaps be found when one considers the Golgi apparatus itself.

It is not disputed that the Golgi is composed of several structurally and functionally distinct regions. These regions would include the "traditional" cis, me- dial, and trans cisterna, plus the trans-Golgi network and, according to some authors, possibly a cis-Golgi network. However, there are two fundamentally different models that strive to explain how this organelle is formed (for reviews see [28, 67, 73-75]). In essence, one model postulates the Golgi as a "fixed" structure, connected by transport vesicles that bud from one region (say, the cis-Golgi) and fuse with the next (in this case, the medial Golgi), thus permitting a continuous anterograde flow of cargo molecules, with concomitant recycling of vesicular elements back to their original compartment, in both cases using COPI-coated carriers $[28,74]$. The alternative, which has accumulated con-

FIG. 6. NSF and alfa-SNAP are prominent on the mouse acrosome. In spermatocytes (A) NSF shows a diffuse cytoplasmic label with a slight concentration reminiscent of the Golgi apparatus (asterisk, see Fig. 1A). In round spermatids NSF labels the acrosomal vesicle (B) and, in later stages, the acrosome, as it spreads over the nucleus (C, D). $\alpha$-SNAP (green) has a similar labeling pattern in both early (E) and late $(F)$ stages of acrosome formation in round spermatids. Bar represents $5 \mu \mathrm{m}$. (G) Both proteins are detected by Western blot as single bands at the appropriate molecular weights (approximately $66 \mathrm{kDa}$ for NSF and $34 \mathrm{kDa}$ for alfa-SNAP). 

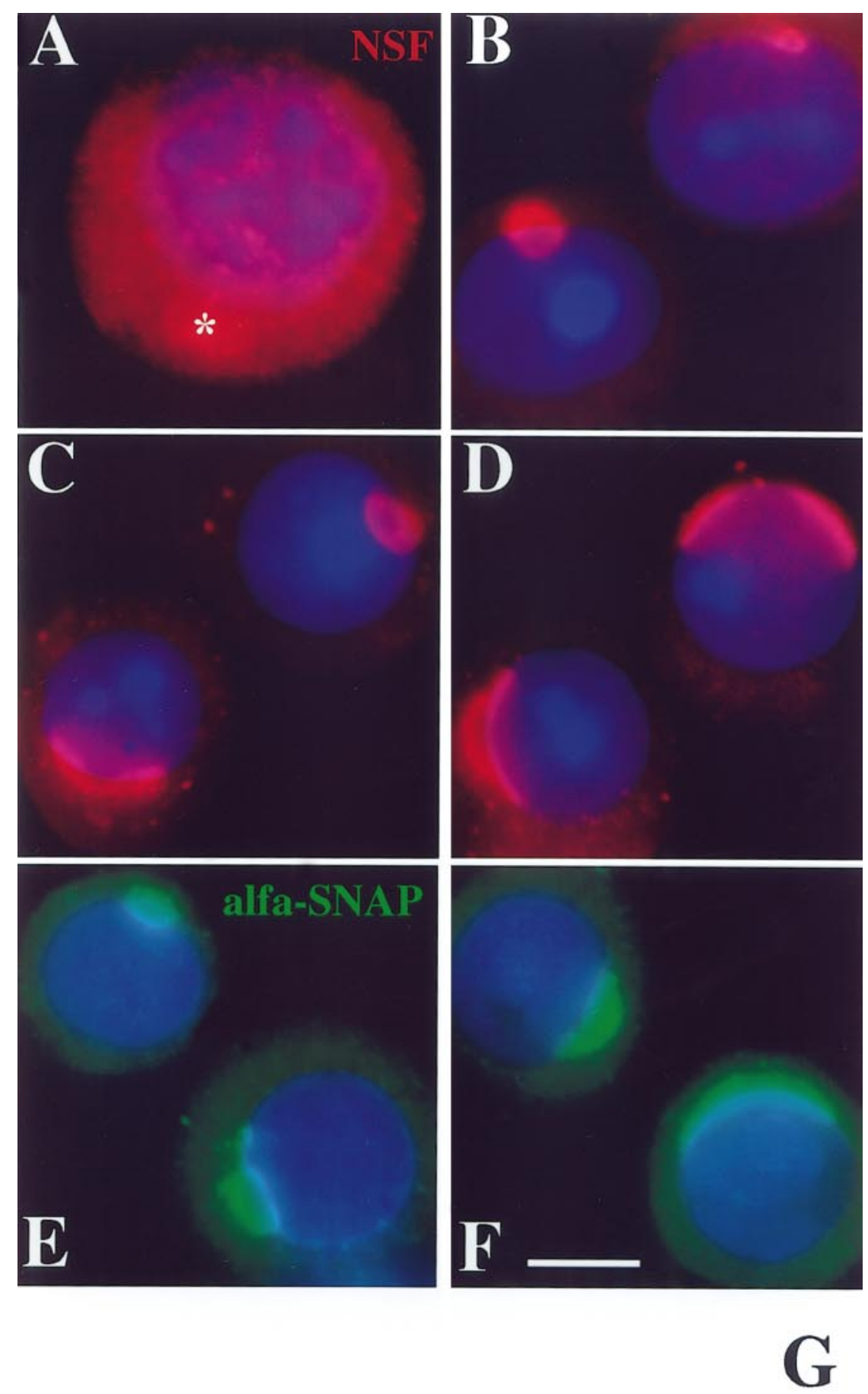

NSF

$\square 91$

non
alfa-SNAP

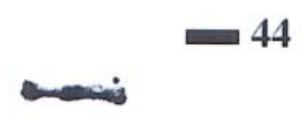

$\square 5$ 

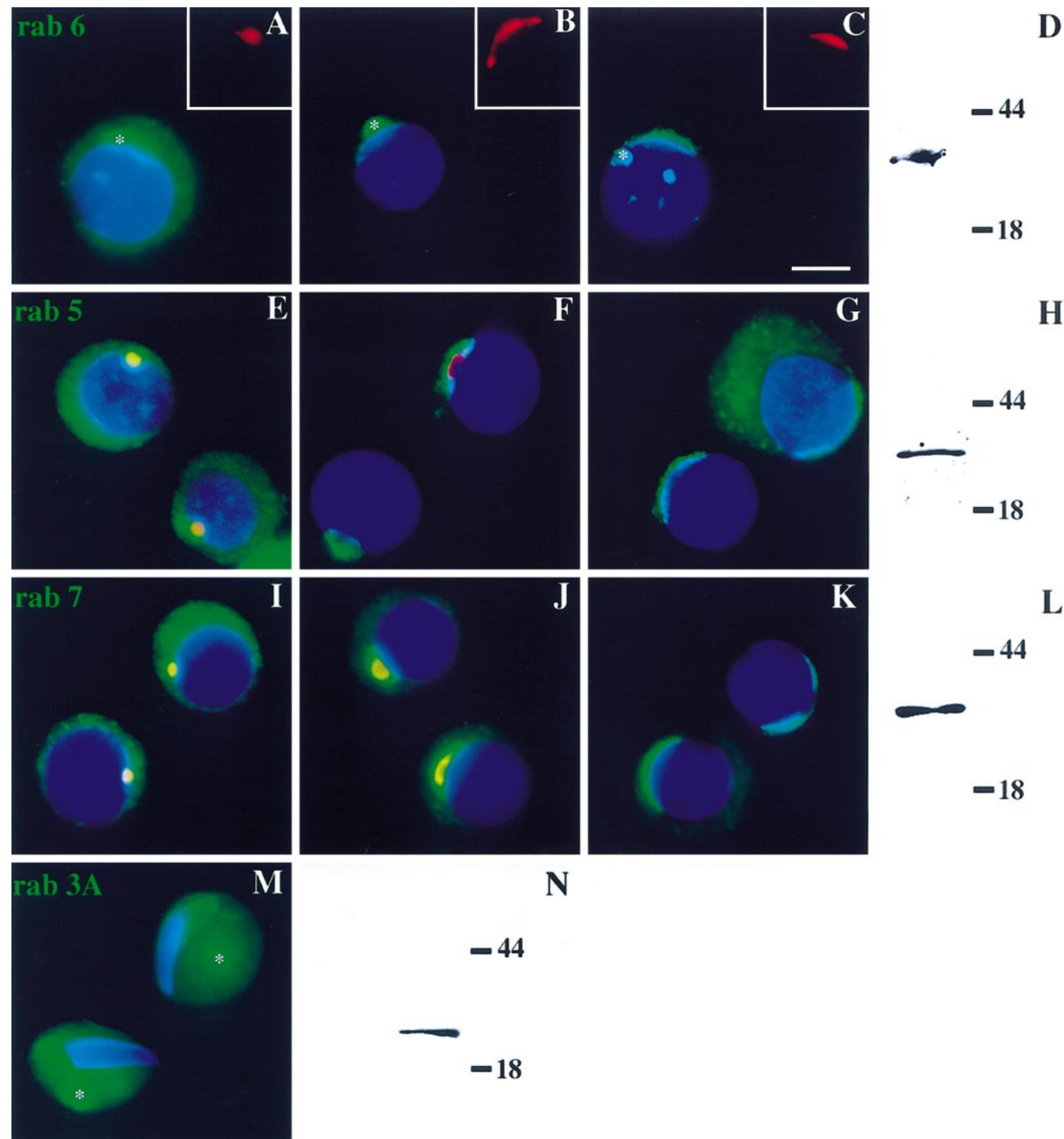

$\mathbf{N}$

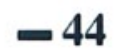

FIG. 7. rab proteins are associated with the acrosome during spermiogenesis. Several small GTPases of the rab family (green) are present on the acrosome, identified in some cases using sp56 as an acrosomal marker (red; for clarity insets for sp56 staining were used on occasion). Rab6 (A-D) is found mainly on the Golgi apparatus (asterisks), but can also be detected as a fainter acrosomal label, both when the Golgi is in close association with the nascent vesicle (A, B) and after it has started its migration to the opposite cell pole (C). Rab5 (E-H) is found as a diffuse cytoplasmic label in early Gol gi-phase round spermatids, with a slight ring around the acrosomal granule (E); but, at later stages, is concentrated around the acrosome in a dotted pattern ( $F, G)$. Rab7 (I-L) shows a pattern very similar to rab5. Although rab3A ( $M, N)$ is found in the acrosome of mature sperm (not shown) it could be detected only on the Gol gi apparatus of round spermatids, not on the acrosome (not shown). In el ongating spermatids (M) this rab was still present in the Gol gi apparatus (asterisks) and also localized to the manchette, but not to the acrosome. DNA is shown in blue; bar represents $5 \mu \mathrm{m}$. Following Western blot analysis, D (rab6), H (rab5), L (rab7), and N (rab3A) show that in each case the probes used detect single bands of the molecular weight (20-30 kDa) expected for rab proteins. 
vincing evidence in recent years, is named the "maturation" model, and recent ultrastructural evidence suggests that it might be applicable to the Golgi apparatus in spermatids [76]. According to this model, Golgi cisternae are continually formed "de novo," and added at the cis-side of the organelle. The cisternae then pass through the organelle, receiving transport COPIcoated vesicles that recycle Golgi resident proteins in the trans-cis direction. For example, in this case a medial cisterna would carry all anterograde cargo inside (rather than package it into transport vesicles) and would gradually become a trans cisterna by both receiving recycled proteins from more mature cisterna and, in turn, delivering its own "medial-specific" proteins to a cisterna closer to the cis end of the organelle. Incomplete recycling would explain why some proteins, although highly enriched in one area of the organelle, might also be found in other regions. After passing through the entire complex the trans-most cisternae would then be dismantled at the TGN, with Golgi elements being retrieved and the remaining components forming nascent secretory granules and other types of vesicular/tubular carriers destined to the plasma membrane, Iysosomes, etc. [28, 67, 73, 75].

With the maturation model framework in mind, it is therefore possible that, in spermatids, the Golgi flux is functionally directed to, and thus ends in, this specialized structure. Rather than being viewed as missorted, Golgi antigens may arrive at the acrosome simply by following this continuous flow of membranes. The acrosome would then be the final compartment where recycling/retrieval takes place, thus explaining the presence of COPI components and rab6, and the relative abundance of Gol gi proteins on this organelle could be related to diverse recycling kinetics. The decrease in acrosomal membrane during the final acrosome phase of spermatid maturation $[77,78]$ could reflect this phenomenon. This model is also reminiscent of the sorting and recycling events that take place during the biogenesis/maturation of Golgi-derived secretory granules [79].

Although, as discussed above, the presence of giantin and $\beta$-COP on the acrosome likely reflects COPI-mediated recycling of proteins back to the Golgi $[13,14]$, it remains to be established whether the presence of other Golgi proteins has any physiological relevance to the maturation of the organelle itself [26].

The intense trafficking that occurs during acrosome biogenesis (albeit possibly at a very slow rate, since spermiogenesis may take up to 14 days in the mouse), suggests that players normally involved in intracellular membrane traffic/fusion in somatic cells may play a role during the growth and shaping of this organelle. Given their importance in other trafficking events (for reviews see $[28,29]$ ) SNARE proteins seemed likely candidates, and we have de- scribed here that homologues of syntaxin and VAMP are distinctively present on the acrosome since this organelle first begins to take shape. Although their exact function is not clear, it is likely that the tSNARE syntaxin may interact with the v-SNARE VAMP to mediate docking/fusion of Golgi-derived vesicles during acrosome formation. The fact that these proteins so distinctively label the acrosomal vesicle, and that this label is paralleled by the presence of NSF and alfa-SNAP, again stresses the biogenesis of this organelle as the major membrane trafficking event to take place during spermiogenesis and points to NSF, SNAPs, and SNAREs as possible players in membrane trafficking and fusion events that underlie acrosome growth and shaping. That these proteins are present during acrosome biogenesis is not surprising, given that NSF and SNAPs are active in most intracelular trafficking events [27, 29], that VAMP homologues play a role in many SNARE-mediated fusion events, and that at least one member of the syntaxin family has been found to participate in all the events described so far $[28,57,80]$.

Results obtained with SNAREs and rab proteins in this study seem to suggest that the acrosome may be a unique structure, with several pathways converging, and possibly contributing to, its biogenesis. While the presence of rab6, as well as syntaxin 1 and VAMP1, on this organelle suggests that it should be classified as a specialized secretory granule, the presence of rab5 raises the possibility that the endocytic pathway (probably via early endosomes) might also contribute to acrosome formation. Additionally, rab7 has been implicated in lysosome biogenesis [66], and the acrosome could therefore also be viewed as a (secretory) lysosome [5-7]. However, further work is needed to expand this hypothesis, since it is possible that the probes developed against components of the trafficking machinery in somatic cell also recognize a similar (possibly even testis-specific) protein. Future studies will therefore focus on the pressing questions regarding the precise molecular nature and activity of the SNARE homologues involved in acrosome formation, as well as on other regulators of membrane traffic that might also participate in this process.

We thank Bryan McVay and Diana Takahashi for technical assistance, as well as Hollie Wilson, Nancy Duncan, and Michelle Emme for editorial support. This work was supported by research grants from the NIH (NICHD, NCRR) to G.S. The ORPRC is sponsored as an NCRR Regional Primate Research Center. J . R.-S. is the recipient of a Praxis XXI postdoctoral fellowship from $\mathrm{F}$ undação para a Ciência e Tecnologia (FCT, Portugal) and thanks D. Santos, H. Santos, J . C. Fernandes, J . M. Lameiras, J . P. Boléo, J . P. Cotrim, M. Caldas, H. Pratt, C. Maltese, F. Schuiten, and B. Peeters for their encouragement and inspiration. 


\section{REFERENCES}

1. Nolan, J. P., and Hammerstedt, R. H. (1997). Regulation of membrane stability and the acrosome reaction in mammalian sperm. FASEB J . 11, 670-682.

2. Breitbart, H., and Spungin, B. (1997). The biochemistry of the acrosome reaction. Mol. Hum. Reprod. 3, 195-202.

3. Allison, A. C., and Hartree, E. F. (1970). Lysosomal enzymes in the acrosome and their possible role in fertilization. J . Reprod. Fertil. 21, 501-515.

4. Moreno, R. D., Ramalho-Santos, J., Wessel, G. M., Chan, E. K. L., and Schatten, G. (2000). The Golgi apparatus segregates from the lysosomal/acrosomal vesicle during rhesus spermiogenesis: Structural alterations. Dev. Biol. 219, 334-349.

5. Andrews, N. W. (2000). Regulated secretion of conventional lysosomes. Trends Cell Biol. 10, 316-321.

6. Page, L. J ., Darmon, A. J ., Uellner, R., and Griffiths, G. M. (1998). L is for Iytic granules: Lysosomes that kill. Biochim. Biophys. Acta 1401, 146-156.

7. Rodriguez, A., Webster, P., Ortego, J ., and Andrews, N. W. (1997). Lysosomes behave as $\mathrm{Ca}^{2+}$-regulated exocytic vesicles in fibroblasts and epithelial cells. J . Cell Biol. 137, 93-104.

8. Martinez-Menarguez, J. A., Geuze, H. J ., and Ballesta, J . (1996). Evidence for a nonlysosomal origin of the acrosome. J . Histochem. Cytochem. 44, 313-320.

9. Peterson, R. N., Bozzola, J., and Polakoski, K. (1992). Protein transport and organization of the developing mammalian sperm acrosome. Tissue Cell 24, 1-15.

10. Burgos, M. H., and Gutierrez, L. S. (1986). The Golgi complex of the early spermatid in guinea pig. Anat. Rec. 216, 139-145.

11. Olson, G. E., Winfrey, V. P., and NagDas, S. K. (1998). Acrosome biogenesis in the hamster: Ultrastructurally distinct matrix regions are assembled from a common precursor polypeptide. Biol. Reprod. 58, 361-370.

12. Griffiths, G., Warren, G., Stuhlfauth, I., and J ockusch, B. M. (1981). The role of clathrin-coated vesicles in acrosome formation. Eur. J. Cell Biol. 26, 52- 60.

13. Moreno, R. D., Ramalho-Santos, J., Sutovsky, P., Chan, E. K. L., and Schatten, G. (2000). Vesicular traffic and Golgi apparatus dynamics during mammalian spermatogenesis: I mplications for acrosome architecture. Biol. Reprod. 63, 89-98.

14. Martinez-Menarguez, J. A., Geuze, H. J., and Ballesta, J . (1996). Identification of two types of beta-COP vesicles in the Golgi complex of rat spermatids. Eur. J . Cell Biol. 71, 137-143.

15. West, A. P., and Willison, K. R. (1996). Brefeldin A and mannose 6-phosphate regulation of acrosomic related vesicular trafficking. Eur. J . Cell Biol. 70, 315-321.

16. Leblond, C. P., and Clermont, Y. (1952). Spermiogenesis of the rat, mouse, hamster and guinea pig as revealed by the 'periodicacid fuchsin sulfurous acid technique.' Am. J . Anat. 90, 167216.

17. Clermont, Y., and Leblond, C. P. (1955). Spermiogenesis of man, monkey, ram and other mammals as shown by the 'periodic acid-Schiff technique.' Am. J . Anat. 96, 22-50.

18. Susi, F. R., Leblond, C. P., and Clermont, Y. (1971). Changes in the Golgi apparatus during spermiogenesis in the rat. Am. J . Anat. 130, 251-267.

19. Hermo, L., Clermont, Y., and Rambourg, A. (1979). Endoplasmic reticulum-Golgi apparatus relationships in the rat spermatid. Anat. Rec. 193, 243-255.

20. Hermo, L., Rambourg, A., and Clermont, Y. (1980). Threedimensional architecture of the cortical region of the Golgi apparatus in rat spermatids. Am. J . Anat. 157, 357-373.
21. Tang, X. M., Lalli, M. F., and Clermont, Y. (1982). A cytochemical study of the Golgi apparatus of the spermatid during spermiogenesis in the rat. Am. J . Anat. 163, 283-294.

22. Thorne-Tjomsland, G., Clermont, Y., and Hermo, L. (1988). Contribution of the Golgi apparatus components to the formation of the acrosomic system and chromatoid body in rat spermatids. Anat. Rec. 221, 591-598.

23. Clermont, Y., Rambourg, A., and Hermo, L. (1994). Connections between the various el ements of the cis- and mid-compartments of the Golgi apparatus of early rat spermatids. Anat. Rec. 240, 469- 480.

24. Clermont, Y., and Tang, X. M. (1985). Glycoprotein synthesis in the Gol gi apparatus of spermatids during spermiogenesis of the rat. Anat. Rec. 213, 33- 43.

25. Tanii, I., Toshimori, K., Araki, S., and Oura, C. (1992). ExtraGolgi pathway of an acrosomal antigen during spermiogenesis in the rat. Cell Tissue Res. 270, 451- 457.

26. Igdoura, S. A., Herscovics, A., Lal, A., Moremen, K. W., Morales, C. R., and Hermo, L. (1999). Alpha-mannosidases involved in $\mathrm{N}$-glycan processing show cell specificity and distinct subcompartmentalization within the Golgi apparatus of cells in the testis and epididymis. Eur. J . Cell Biol. 78, 441- 452.

27. Rothman, J. E. (1994). Mechanisms of intracellular protein transport. Nature 372, 55- 63.

28. Nichols, B. J ., and Pelham, H. R. (1998). SNAREs and membrane fusion in the Golgi apparatus. Biochim. Biophys. Acta 1404, 9-31.

29. Pfeffer, S. R. (1999). Transport-vesicletargeting: Tethers before SNAREs. Nat. Cell Biol. 1, E17-22.

30. Sutovsky, P., Ramalho-Santos, J., Moreno, R. D., Oko, R., Hewitson, L., and Schatten, G. (1999). On-stage selection of single round spermatids using a vital, mitochondrion-specific fluorescent probe MitoTracker(TM). and high resolution differential interference contrast microscopy. Hum. Reprod. 14, 2301-2312.

31. Otter-Nilsson, M., Hendriks, R., Pecheur-Huet, E. I., Hoekstra, D., and Nilsson, T. (1999). Cytosolic ATPases, p97 and NSF, are sufficient to mediate rapid membrane fusion. EMBO J. 18, 2074-2083.

32. Brugger, B., Nickel, W., Weber, T., Parlati, F., McNew, J . A., Rothman, J. E., and Sollner, T. (2000). Putative fusogenic activity of NSF is restricted to a lipid mixture whose coalescence is also triggered by other factors. EMBO J . 19, 1272-1278.

33. Michaut, M., Tomes, C. N., De Blas, G., Yunes, R., and Mayorga, L. S. (2000). Calcium-triggered acrosomal exocytosis in human spermatozoa requires the coordinated activation of Rab3A and N-ethylmaleimide-sensitive factor. Proc. Natl. Acad. Sci. USA 97, 9996-10001.

34. Martinez, O., and Goud, B. (1998). Rab proteins. Biochim. Biophys. Acta 1404, 101-112.

35. Somsel Rodman, J ., and Wandinger-Ness, A. (2000). Rab GTPases coordinate endocytosis. J . Cell Sci. 113(Pt. 2)., 183-192.

36. Garde, J., and Roldan, E. R. (1996). rab 3-peptide stimulates exocytosis of the ram sperm acrosome via interaction with cyclic AMP and phospholipase A2 metabolites. FEBS Lett. 391, 263268.

37. Iida, H., Yoshinaga, Y., Tanaka, S., Toshimori, K., and Mori, T. (1999). Identification of Rab3A GTPase as an acrosome-associated small GTP-binding protein in rat sperm. Dev. Biol. 211, 144-155.

38. Yunes, R., Michaut, M., Tomes, C., and Mayorga, L. S. (2000). Rab3A triggers the acrosome reaction in permeabilized human spermatozoa. Biol. Reprod. 62, 1084-1089. 
39. Ward, C. R., Faundes, D., and Foster, J . A. (1999). The monomeric GTP binding protein, rab3a, is associated with the acrosome in mouse sperm. Mol. Reprod. Dev. 53, 413- 421.

40. Geppert, M., Bolshakov, V. Y., Siegelbaum, S. A., Takei, K., De Camilli, P., Hammer, R. E., and Sudhof, T. C. (1994). The role of Rab3A in neurotransmitter release. Nature 369, 493- 497.

41. Conner, S., Leaf, D., and Wessel, G. (1997). Members of the SNARE hypothesis are associated with cortical granule exocytosis in the sea urchin egg. Mol. Reprod. Dev. 48, 106-118.

42. Foster, J. A., Friday, B. B., Maulit, M. T., Blobel, C., Winfrey, V. P., Olson, G. E., Kim, K. S., and Gerton, G. L. (1997). AM67, a secretory component of the guinea pig sperm acrosomal matrix, is related to mouse sperm protein sp56 and the complement component 4-binding proteins. J . Biol. Chem. 272, 1271412722.

43. Griffith, K. J ., Chan, E. K., Lung, C. C., Hamel, J . C., Guo, X., Miyachi, K., and Fritzler, M. J . (1997). Molecular cloning of a novel 97-kD Golgi complex autoantigen associated with Sjogren's syndrome. Arthritis Rheum. 40, 1693-1702.

44. Chan, E. K. L., and Fritzler, M. J . (1998). Golgins: Coiled-coilrich proteins associated with the Golgi complex. Electronic J. Biotech. 1, 1-10. Available at http:/ejb.org/content/vol 1/ issue2/full/1/index.html

45. Fritzler, M. J ., Hamel, J . C., Ochs, R. L., and Chan, E. K. (1993). Molecular characterization of two human autoantigens: Unique cDNAs encoding 95- and 160-kD proteins of a putative family in the Golgi complex. J . Exp. Med. 178, 49-62.

46. Bellve, A. R. (1993). Purification, culture, and fractionation of spermatogenic cells. Methods Enzymol. 225, 84-113.

47. Bavister, B. D., Boatman, D. E., Leibfried, L., Loose, M., and Vernon, M. W. (1983). Fertilization and cleavage of rhesus monkey oocytes in vitro. Biol. Reprod. 28, 983-999.

48. Pagano, R. E., Martin, O. C., Kang, H. C., and Haugland, R. P. (1991). A novel fluorescent ceramide analogue for studying membrane traffic in animal cells: Accumulation at the Golgi apparatus results in altered spectral properties of the sphingolipid precursor. J . Cell Biol. 113, 1267-1279.

49. Arboleda, C. E., and Gerton, G. L. (1988). Proacrosin/acrosin during guinea pig spermatogenesis. Dev. Biol. 125, 217-225.

50. Bozzola, J. J ., Polakoski, K., Haas, N., Russell, L. D., Campbell, P., and Peterson, R. N. (1991). Localization of boar sperm proacrosin during spermatogenesis and during sperm maturation in the epididymis. Am. J. Anat. 192, 129-141.

51. Westbrook-Case, V. A., Winfrey, V. P., and Olson, G. E. (1995). Sorting of the domain-specific acrosomal matrix protein AM50 during spermiogenesis in the guinea pig. Dev. Biol. 167, 338349.

52. Kurth, B. E., Klotz, K., Flickinger, C. J ., and Herr, J . C. (1991). Localization of sperm antigen SP-10 during the six stages of the cycle of the seminiferous epithelium in man. Biol. Reprod. 44, 814- 821.

53. Lippincott-Schwartz, J., Yuan, L. C., Bonifacino, J. S., and Klausner, R. D. (1989). Rapid redistribution of Golgi proteins into the $E R$ in cells treated with brefeldin A: Evidence for membrane cycling from Golgi to ER. Cell 56, 801- 813.

54. Torii, S., Banno, T., Watanabe, T., Ikehara, Y., Murakami, K., and Nakayama, K. (1995). Cytotoxicity of brefeldin A correlates with its inhibitory effect on membrane binding of COP coat proteins. J . Biol. Chem. 270, 11574-11580.

55. Ramalho-Santos, J., Moreno, R. D., Sutovsky, P., Chan, A. W. S., Hewitson, L., Wessel, G. M., Simerly, C. R., and Schatten, G. (2000). SNAREs in mammalian sperm: Possible implications for fertilization. Dev. Biol. 223, 54- 69.
56. Hewitson, L., Dominko, T., Takahashi, D., Martinovich, C., Ramalho-Santos, J ., Sutovsky, P., Fanton, J ., J acob, D., Monteith, D., Neuringer, M., Battaglia, D., Simerly, C., and Schatten, G. (1999). Unique checkpoints during the first cell cycle of fertilization after intracytoplasmic sperm injection in rhesus monkeys. Nat. Med. 5, 431- 433.

57. Calakos, N., and Scheller, R. H. (1996). Synaptic vesicle biogenesis, docking, and fusion: A molecular description. Physiol. Rev. 76, 1-29.

58. Hay, J . C., Klumperman, J ., Oorschot, V., Steegmaier, M., Kuo, C. S., and Scheller, R. H. (1998). Localization, dynamics, and protein interactions reveal distinct roles for $E R$ and Golgi SNAREs. J . Cell Biol. 141, 1489-1502.

59. Subramaniam, V. N., Krijnse-Locker, J ., Tang, B. L., Ericsson, M., Yusoff, A. R., Griffiths, G., and Hong, W. (1995). Monoclonal antibody HFD9 identifies a novel $28 \mathrm{kDa}$ integral membrane protein on the cis-Golgi. J . Cell Sci. 108, 2405-2414.

60. Lowe, S. L., Peter, F., Subramaniam, V. N., Wong, S. H., and Hong, W. (1997). A SNARE involved in protein transport through the Golgi apparatus. Nature 389, 881- 884.

61. White, J., J ohannes, L., Mallard, F., Girod, A., Grill, S., Reinsch, S., Keller, P., Tzschaschel, B., Echard, A., Goud, B., and Stelzer, E. H. (1999). Rab6 coordinates a novel Gol gi to ER retrograde transport pathway in live cells. J. Cell Biol. 147, 743-760.

62. Girod, A., Storrie, B., Simpson, J. C., J ohannes, L., Goud, B., Roberts, L. M., Lord, J. M., Nilsson, T., and Pepperkok, R. (1999). Evidence for a COP-I-independent transport route from the Golgi complex to the endoplasmic reticulum. Nat. Cell Biol . 1, 423- 430 .

63. I ida, H., Tanaka, S., and Shibata, Y. (1997). Small GTP-binding protein, Rab6, is associated with secretory granules in atrial myocytes. Am. J . Physiol. 272, C1594-1601.

64. Stenmark, H., Vitale, G., Ullrich, O., and Zerial, M. (1995). Rabaptin-5 is a direct effector of the small GTPase Rab5 in endocytic membrane fusion. Cell 83, 423- 432.

65. Trischler, M., Stoorvogel, W., and Ullrich, O. (1999). Biochemical analysis of distinct Rab5- and Rab11-positive endosomes along the transferrin pathway. J . Cell Sci. 112, 4773- 4783.

66. Bucci, C., Thomsen, P., Nicoziani, P., McCarthy, J ., and van Deurs, B. (2000). Rab7: A key to lysosome biogenesis. Mol. Biol. Cell 11, 467- 480 .

67. Lowe, M., and Kreis, T. E. (1998). Regulation of membrane traffic in animal cells by COPI. Biochim. Biophys. Acta 1404, 53- 66.

68. Peyroche, A., Paris, S., and J ackson, C. L. (1996). Nucleotide exchange on ARF mediated by yeast Geal protein. Nature 384, 479- 481.

69. Peyroche, A., Antonny, B., Robineau, S., Acker, J ., Cherfils, J ., and J ackson, C. L. (1999). Brefeldin A acts to stabilize an abortive ARF-GDP-Sec7 domain protein complex: I nvolvement of specific residues of the Sec7 domain. Mol. Cell 3, 275-285.

70. Whitney, J . A., Gomez, M., Sheff, D., Kreis, T. E., and Mellman, I. (1995). Cytoplasmic coat proteins involved in endosome function. Cell 83, 703-713.

71. Aniento, F., Gu, F., Parton, R. G., and Gruenberg, J . (1996). An endosomal beta COP is involved in the $\mathrm{pH}$-dependent formation of transport vesicles destined for late endosomes. J . Cell Biol. 133, 29- 41.

72. Daro, E., Sheff, D., Gomez, M., Kreis, T., and Mellman, I. (1997). Inhibition of endosome function in $\mathrm{CHO}$ cells bearing a 
temperature-sensitive defect in the coatomer (COPI). component epsilon-COP. J . Cell Biol. 139, 1747-1759.

73. Glick, B. S., and Malhotra, V. (1998). The curious status of the Golgi apparatus. Cell 95, 883- 889.

74. Schekman, R., and Mellman, I. (1997). Does COPI go both ways? Cell 90, 197-200.

75. Allan, B. B., and Balch, W. E. (1999). Protein sorting by directed maturation of Golgi compartments. Science 285, 63- 66.

76. Ho, H. C., Tang, C. Y., and Suarez, S. S. (1999). Threedimensional structure of the Golgi apparatus in mouse spermatids: A scanning electron microscopic study. Anat. Rec. 256, 189-194.

Received May 31, 2000

Revised version received November 27, 2000
77. Courtens, J . L. (1978). Release of carbohydrate-containing vesicles by the developing acrosomes of ram spermatids-relation to morphometric changes of the acrosome. J . Ultrastruct. Res. 65, 182-189.

78. Pelletier, R. M., and Friend, D. S. (1983). Development of membrane differentiations in the guinea pig spermatid during spermiogenesis. Am. J . Anat. 167, 119-141.

79. Arvan, P., and Castle, D. (1998). Sorting and storage during secretory granule biogenesis: Looking backward and looking forward. Biochem. J . 332, 593-610.

80. Advani, R. J ., Yang, B., Prekeris, R., Lee, K. C., Klumperman, J ., and Scheller, R. H. (1999). VAMP-7 mediates vesicular transport from endosomes to lysosomes. J. Cell Biol. 146, 765-776. 